adult form. Clin Neurol Neurosurg 1976;79:307-15.

34 Scheithauer BW, Forno LS, Dorfman LJ, Kane CA. Neuroaxonal dystrophy (Seitelberger's disease) with late onset, protracted course and myoclonic epilepsy. $J$ Neurol Sci 1978;36:247-58.

35 Hartmann HA, White SK, Levine RL. Neuroaxonal dystrophy with neuromelanin deposition, neurofibrillary tangles, and neuronal loss. Light- and electron microscopic changes in a $\mathbf{4 5}$ year old woman with progressive psychomotor deterioration. Acta Neuropathol (Berl) 1983;61:169-72.

Accepted 17 April 1986

\section{Stridor during dystonic phases of Parkinson's disease}

Sir: Stridor is very rare in both idiopathic Parkinson's disease ${ }^{1}$ and in Parkinsonism after encephalitis lethargica ${ }^{2}$ and contrasts with the Shy-Drager syndrome in which it regularly occurs due to selective paralysis of abduction of the vocal cords. ${ }^{3}$ We describe, in two patients with longstanding idiopathic and levodopa responsive Parkinson's disease, severe attacks of stridor during phases when they were dystonic elsewhere.

In March 1986, a 66 year old man was referred by his physician because of episodic breathing difficulties. In 1978 he had developed a left sided resting tremor. There was a satisfactory response to levodopa/carbidopa and benzhexol. Two years later while on Sinemet 275 , two tablets daily and benzhexol $2 \mathrm{mg}$ bd, he reported painful curling up of the toes of his left foot soon after awakening. These episodes persisted despite an increase of levodopa to Sinemet 275, three tablets daily. By 1984 he noted that in addition to dystonic posturing of his left foot, he simultaneously found difficulty with breathing, particularly inspiration. Shifting the evening dose of Sinemet from 1800 to 2200 hours resulted in a reduction in the incidence of this problem, but dystonia tended to recur at the time the next dose of Sinemet was due. By taking Sinemet 275 half a tablet every 2 hours, dystonic episodes were avoided.

In order to better understand the nature of his breathing problems we arranged to observe one of his dystonic episodes after the omission of one dose so that it was then four hours after his last dose of Sinemet. The attack began with sustained inversion and plantar flexion of the left foot with flexion of the toes. A few minutes later he developed mild retrocollis and became apprehensive. His breathing became laboured with the development of stridor. He made loud gagging noises and repeatedly raised his hands to his throat as if being strangled. He was unable to speak. Sustained dystonic contractions of all the facial muscles including platysma were seen. $\mathrm{He}$ slipped down his armchair into a most ungainly posture so that the back of his head rested on the back of the chair. He said afterwards that he usually lay supine during an attack, presumably because the retrocollis is somewhat relieved. His distressing ordeal was ended when he took another full tablet of Sinemet 275 with rapid improvement in stridor, although dystonic posturing of the left foot persisted for over an hour. Careful examination of his vocal cords showed no abnormality though it was not possible to examine them during the attack.

Parkinson's disease was diagnosed in the second patient at the age of 45 years following the development of clumsiness and slowness of movement of the left arm and leg. He became asymptomatic on levodopa until age 54 when peak dose choreiform dyskinesia was noted. Orphenadrine had been added to his treatment regime earlier. A year later he developed visual hallucinations and Sinemet 110 was reduced from three to two tablets daily. Three days later he developed intermittent breathing difficulties, stridor and dysphonia with dystonic retraction of the jaw, wide gaping of the mouth with facial grimacing. The episodes were particularly distressing to the patient and his wife at night. On admission to hospital mechanical obstruction to the airway was considered, but urgent indirect laryngoscopy was normal showing a full range of movement of the vocal cords. It was observed, however, that by forcibly pulling the jaw forward the stridor could be relieved. The dystonia was thought to be due to an under dosage of levodopa so Sinemet 110 was increased to four tablets daily. After two days the episodes of dystonic stridor ceased. A month later his Sinemet dose had to be decreased owing to the recurrence of confusion and hallucinations. Two months later, there was a further emergency admission for respiratory distress and stridor. The dystonic features were similar but more severe than during previous admissions. The patient was semi-conscious, restless and unco-operative and an anaesthetist considered that the obstruction to the airway was so critical that urgent tracheostomy was required. A minitracheostomy tube was inserted and he rapidly became more settled. The tube was left in situ for seven days while his Sinemet regime was increased to half a tablet six times daily. There has been no recurrence of stridor during three months follow-up on $\frac{\mathbb{C}}{\bar{D}}$ this regime.

The mechanism of stridor in these two $Z_{\Phi}$ cases seemed to differ from the laryngeal spasm previously described in Parkinson's disease $^{1}$ in that the main obstruction to airflow occurred above the level of the larynx. The vocal cords were not adducted in either patient, thus it seems likely that dystonia of the pharyngeal, jaw and neck muscles played a significant part. Breathing difficulties of this sort have been described.. rarely in the late stages of dystonia musculorum deformans, ${ }^{4}$ and in adults with $\stackrel{\text { ? }}{+}$ oro-mandibular dystonia who developed neck involvement. 56

Dystonic responses to levodopa therapy $\frac{\overline{\mathcal{C}}}{\partial}$ are well recognised in Parkinson's disease $\overparen{D}$ and various patterns have been described. ${ }^{7-10}$ The lack of previous descrip- $\omega$ tions of dystonic stridor in Parkinson's dis- $\overrightarrow{0}$ ease is surprising but it may be a nearterminal event and hence overlooked as a $\vec{\omega}$ complete neurological assessment at this stage is rare. Secondly, patients may be living longer because of the support of levodopa allowing new clinical phenomena o related to its use to be observed. The dy叉tonia in both our patients responded $\$ p$ higher doses of levodopa and therefofe appears to be an under dosage phenomenom. 을

The spectrum of clinical phenomega classified as dystonic has widened in recentc years; for example, spasmodic dysphonia $s$ s now recognised as being a form of focal d tonia of the laryngeal muscles. ${ }^{1112}$ Whether $\vec{r}$ some instances of stridor, currenty classified as hysterical, come to be recognised as a form of segmental dystonia remains to be seen.

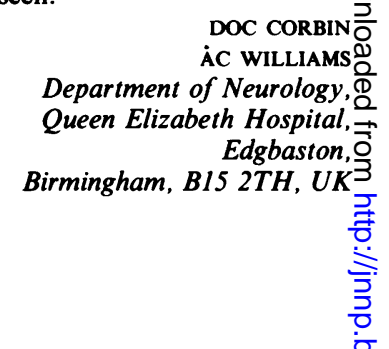

1 Vas CJ, Parsonage M, Lord OC. Parkinsonism associated with laryngeal spasm. J Neurol Neurosurg Psychiatry 1965;28:401-3.

2 Turner WA, Critchley M. Respiratory disorders in epidemic encephalitis. Brain 음 1925;48:72-104.

3 Williams A, Hanson D, Calne DB. Vocal cord $\frac{D}{O}$ paralysis in the Shy-Drager syndrome. J Neurol Neurosurg Psychiatry 1979;42:151-3.

4 Marsden CD, Marion M-H, Quinn N. The o treatment of severe dystonia in children and $\mathrm{N}$ adults. J Neurol Neurosurg Psychiatry 1984;47:1166-73. 
5 Marsden CD. The problem of adult-onset idiopathic torsion dystonia and other isolated dyskinesias in adult life (including blepharospasm, oromandibular dystonia, dystonic writer's cramp and torticollis or axial dystonia). In: Eldridge R, Fahn S, eds. Advanced in Neurology. Vol. 14. New York: Raven Press, 1976:259-76.

6 Garcia-Albea E, Franch O, Mundoz D, Ricoy JR. Brueghel's syndrome, report of a case with post-mortem study. J Neurol Neurosurg Psychiatry 1981;44:437-40.

7 Barbeau A. Disphasic dyskinesias during levodopa therapy. Lancet 1975;1:756.

8 Muenter MD, Sharpless NS, Tyce GN, Darley FL. Patterns of dystonia (I-D-I and D-I-D) in response to L-dopa therapy in Parkinson's disease. Mayo Clin Proc 1977;52:163-74.

9 Lhermitte F, Agid Y, Signoret JL. Onset and end of dose levodopa-induced dyskinesias. Arch Neurol 1978;35:261-3.

10 Agid Y, Bonnet A, Signoret J, Lhermitte F. Clinical pharmacological and biochemical approach of "onset and end of dose" dyskinesias. In: Poirier LJ, Sourkes TL, Bedard PJ, eds. Advances in Neurology. Vol. 24. New York: Raven Press, 1979:401-10.

11 Aminoff MJ, Dedo HH, Izdebski K. Clinical aspects of spasmodic dysphonia. $J$ Neurol Neurosurg Psychiatry 1978;48:218-24.

12 Anonymous. Spasmodic dysphonia. Lancet (Editorial) 1984;2:1192.

Accepted 6 November 1986

Schistosoma mansoni in the spinal cord: a correlation between operative and radiological findings

Sir: Neurological complications of Schistosoma mansoni are, although rare, well documented. ${ }^{12}$ Schistosomiasis is endemic in many parts of the world, ${ }^{1}$ and with man as the primary host, the schistosomes have a complex life cycle involving a specific secondary host, a water snail. Having entered the body of the primary host, the parasites are carried via the blood and lymphatic systems to the liver where maturation into adult worms occurs. In the case of Schistosoma mansoni, the adult worms migrate to the veins around the rectum, and there ova are deposited. Owing to the anastomosis formed by a valveless venous plexus between the pelvic veins and the veins of the spinal canal, ${ }^{3}$ ova may spread to involve predominantly the thoraco-lumbar area of the spinal canal. We describe such a case.

A 15 year old boy from Kano State, Nigeria, presented in November 1985 with a one year history of weakness in his left leg and two months of weakness in his right leg associated with some difficulty with mictu- rition. He had previously been well apart from an 8 month period of back pain in 1980. The abnormal findings on examination were confined to his lower limbs. There was evidence of wasting, fasciculation and a generalised distal weakness. Ankle reflexes were absent and plantar responses equivocal, but sensory examination revealed no abnormality. Haematological investigations including haemoglobin, white cell count and differential, ESR, TPHA and liver function tests were all normal. He was sickle cell negative and the schistosoma enzyme linked immunosorbent assay (Schistosoma ELISA) titre was negative.

Examination of the CSF revealed no abnormality. Specifically, no eosinophils

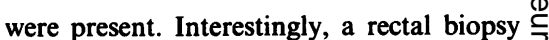
revealed no schistosomal granulomata, and 으 urine examination was negative for hae- $Z$ matobium ova. Chest radiography revealed no abnormality, but plain radiographs of the thoraco-lumbar spine showed an increase in the interpeduncular distance. $A \hat{\Theta}$ Niopam (Iopamidol $300 \mathrm{mg} / \mathrm{ml}$ ) myelogram ${ }_{0}$ and CT myelogram were carried out (fig a, b, c). The myelogram showed widening of $\stackrel{\rho}{?}$. the conus and irregularity in size and shape $\stackrel{\vec{F}}{\overrightarrow{2}}$ of the nerve roots forming the cauda equina, the nerve roots also being matted together $\vec{F}$ (fig a). This was confirmed on CT $\stackrel{\odot}{\longrightarrow}$ myelogram (fig b, c). Particularly moticeable $\bar{C}$ was a beaded appearance along the length of $\bar{\sigma}$ the nerve roots.

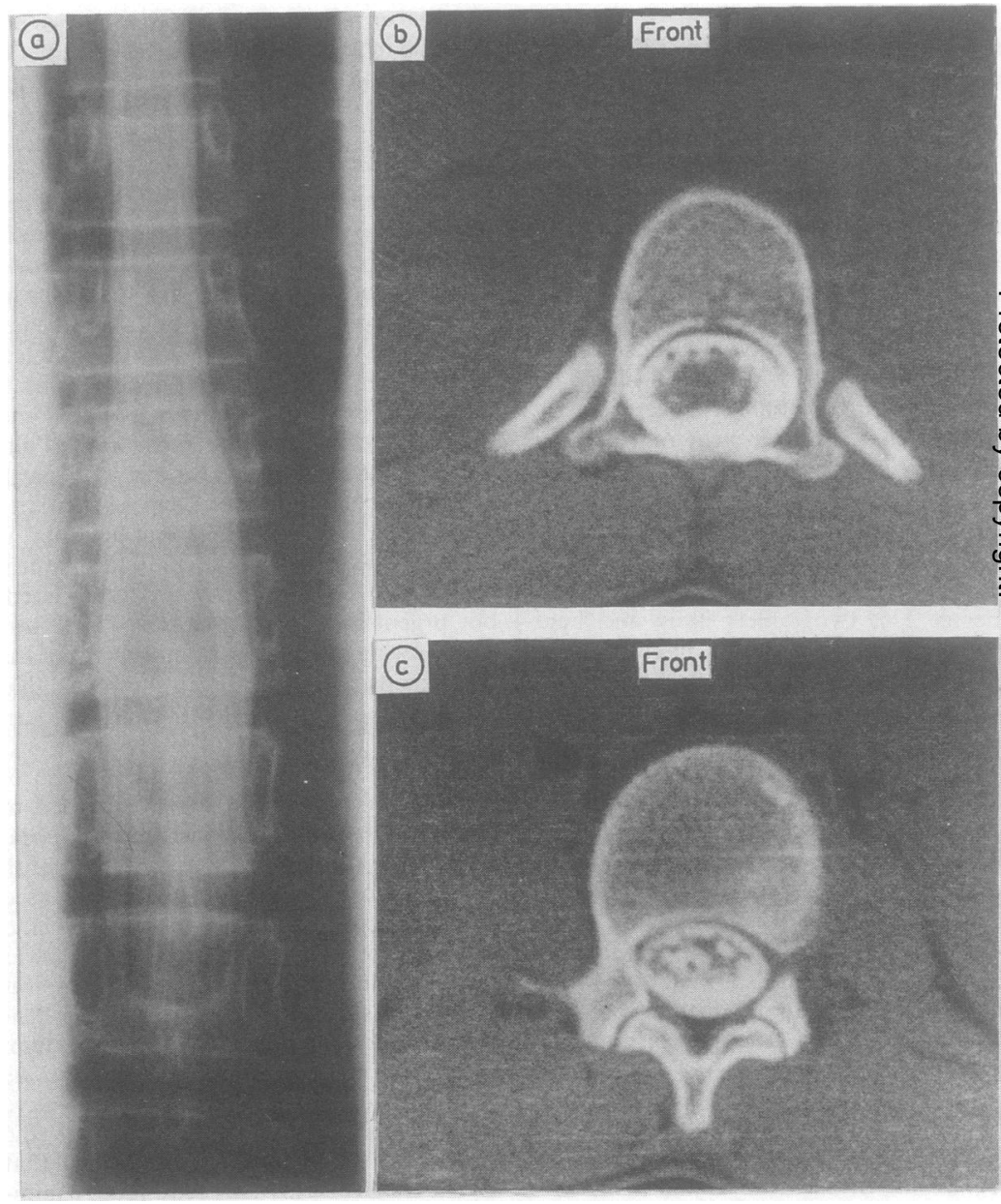

Fig (a) Lumbar myelogram showing widening of the conus and irregularity in size and shape of the nerve roots forming the cauda equina. (Left) (b) CT myelogram showing enlargement in the region of the conus. (Top right) (c) CT myelogram showing irregularity in size of the nerve roots with some clumping of the roots together. (Bottom right). 